\title{
A alfabetização de crianças com seis anos: uma contribuição para \\ o debate sobre aquisição de \\ habilidades de leitura escrita \\ e matemática no primeiro ano \\ do ensino fundamental
}

- Nilma Fontanive*

- Ruben Klein ${ }^{* *}$

- Mariza Abreu ${ }^{* * *}$

— Sônia Elizabeth Bier ${ }^{* * * *}$

\section{Resumo}

O Projeto Piloto de alfabetização foi desenvolvido com alunos da rede pública municipal e estadual do Rio Grande do Sul que ingressaram com seis anos, no ano de 2007, no ensino fundamental de nove anos. Com o objetivo de avaliar os níveis de habilidades de leitura, escrita e matemática, alcançados pelos alunos, foi delineado um experimento separando esses alunos em quatro grupos, sendo que três deles participaram das atividades de aprendizagem conduzidas por três Instituições convidadas, e o outro grupo, de controle, realizou atividades promovidas pelas próprias escolas. Os resultados são apresentados em escalas de proficiências em Leitura, Escrita e Matemática que expressam os desempenhos obtidos pelos alunos ao final do primeiro ano de escolaridade obrigatória. O resultado principal foi que os 3 grupos de intervenção tiveram desempenho melhor em leitura e escrita do que o grupo de controle. Em matemática, não houve diferenças. Foi construída uma medida de nível socioeconômico das escolas dos diferentes grupos e constatou-se que não há diferenças nas distribuições dos níveis socioeconômicos dos 4 grupos.

Palavras-chave: Alfabetização. Avaliação de habilidades de leitura e escrita e matemática. Alfabetização de crianças de seis anos.

\footnotetext{
"Mestre em Educação, Pontifícia Universidade Católica, RJ; Coordenadora de Projetos de Avaliação em Larga Escala, Fundação Cesrganrio.E-mail: nilmaf@cesgranrio.org.br

"* Ph.D. em Matemática, Massachusetts Institute of Technology; Consultor, Fundação Cesgranrio. E-mail: ruben@cesgranrio.org.br

".. Secretária de Estado de Educação do Rio Grande do Sul. E-mail: gothe@seduc.rs.gov.br

"*** Mestre em Educação, Universidade do Vale do Rio dos Sinos (UNISINOS), RS; Consultora da UNESCO Brasil.
} 


\section{The 6-year-old kids literacy: a contribution to the discussion about the acquisition of reading, writing and math skills in the first year of Elementary School Abstract}

This literacy project deals with 6-year-old students that have engaged in the first year of Public Elementary Schools in the state of Rio Grande do Sul in the south of Brazil. Aiming to evaluate the reading, writing and math skills achieved by the students, an experimental model was designed. This model divided the students into four groups, where three of them took part in learning activities conducted by three different institutions, and the fourth, called group of control, took part in activities conducted by the schools themselves. The results of the activities were presented on a reading, writing and math proficiency scale and it showed the development of the students' performance at the end of their first year of school. The main outcome showed that the results of the three groups of intervention were better than the results of the control group in reading and writing and there was no difference in mathematics. A measure of the socioeconomic level of the schools was built and no difference in distribution was found.

Keywords: Literacy. Evaluation of reading, writing and math skills. 6-year-old kids literacy.

\section{La alfabetización de niños con seis años: una contribución para el debate sobre adquisición de habilidades de lectura escrita y matemática en el primero año de la Enseñanza Fundamental Resumen}

El Proyecto Piloto de alfabetización se desenvolvió con alumnos de la rede pública municipal y estadual del Rio Grande do Sul que ingresaran con seis años en 2007, en la enseñanza fundamental de nueve años. Con el objetivo de evaluar los niveles de habilidades de lectura, escrita y matemática, alcanzados por los alumnos, fue delineado un experimento separando los alumnos en cuatro grupos, siendo que tres participaran de actividades de aprendizaje conducidas por tres Instituciones convidadas, y otro grupo, de controle, realizó actividades promovidas por las propias escuelas. Los resultados son presentados en escalas de proficiencias en Lectura, Escrita y Matemática que expresan los desempeños obtenidos por los alumnos al final del primero año de escolaridad obligatoria. El resultado principal fue que los 3 grupos de intervención tuvieran desempeño mejor en lectura y escrita que el grupo de controle. En matemática, no hube diferencias. Fue construida una medida de nivel socioeconómico de las escuelas de los diferentes grupos y se constató que no había diferencias en las distribuciones de los niveles socioeconómicos de los 4 grupos.

Palabras clave: Alfabetización. Evaluación de habilidades de lectura, escrita y matemática. Alfabetización de niños con seis años. 


\section{Justificativa}

A introdução do ensino fundamental de nove anos no Sistema Educacional Brasileiro, no ano de 2006, colocou um desafio para os gestores e professores das redes públicas no sentido de definirem que currículo adotar para desenvolver as habilidades de crianças desta faixa etária. Embora algumas unidades da federação já tenham, há algum tempo, introduzido a aprendizagem de leitura e escrita nas classes de alfabetização, que atendiam crianças dessa idade, não há consenso entre os especialistas de Educação Infantil sobre os programas de ensino e as práticas que os sistemas públicos devem adotar para atender crianças de seis anos no novo ensino fundamental de nove anos.

Esta é uma questão que tem provocado um debate acalorado na comunidade acadêmica e precisa ser analisada com cuidado, pois há argumentos legítimos nos grupos que se colocam a favor ou contra o início formal do processo de alfabetização aos seis anos, sobretudo para aquelas crianças que não tiveram acesso à educação infantil ainda não universalizada em nosso país.

Embora algumas unidades da federação possam apresentar um percentual menor de atendimento, a Pesquisa Nacional por Amostra de Domicílios - PNAD, de 2006, encontrou cerca de 93\% de crianças de seis anos matriculadas nas escolas.

A educação infantil, no Brasil, tem sido um campo de experimentação de práticas pedagógicas inovadoras, com bastante divulgação de idéias e projetos, comprometidos com uma educação que respeita os direitos da criança, tomando-a como sujeito de aprendizagem e como ator social. Para isso, tem-se utilizado de práticas democráticas e de escuta/obsenvação das crianças, que fazem parte da tradição e da inovação da educação pré-escolar no Brasil e no mundo (RAYNA; BROUGÈRE, 2000 apud SANTOS; VIEIRA, 2006).

Segundo as autoras (SANTOS; VIEIRA 2006),

mesmo que as práticas concretas não apresentem hegemonicamente a qualidade desejada e compatível com os conhecimentos acumulados na área dos estudos da infância, a produção teórica e algumas experiências inovadoras vêm oferecendo grandes contribuições. Contribuições estas que podem fortalecer a perspectiva e as intenções de alterar a cultura "escolarizante" do ensino fundamental e oferecer novas abordagens do processo de alfabetização. É isto, portanto, que justifica a vigilância e os esforços de pesquisa e de discussão sobre a temática em foco. Dessa maneira, recomenda-se que a educação da criança de 6 anos no ensino fundamental se nutra desta fonte, avançando cada vez mais na busca de uma educação fundamental de qualidade para todas as crianças e jovens.

Para os especialistas em Educação Infantil, iniciar a alfabetização mais precocemente, sobretudo com crianças de camadas sociais desfavorecidas, que não tiveram a oportunidade de freqüentar a pré-escola ou, que não dispõem em casa de estímulos e materiais próprios de uma cultura letrada, pode comprometer o desenvolvimento cognitivo, emocional e social dessas crianças ao negar-lhes a oportunidade de vivenciar experiências de aprendizagem fundamentais para o sucesso do início da sua escolarização. 
Para Kramer (2006) a educação infantil e ensino fundamental são indissociáveis, pois ambos envolvem conhecimentos e afetos; saberes e valores; cuidados e atenção; seriedade e riso. $\bigcirc$ cuidado, a atenção, o acolhimento estão presentes na educação infantil; a alegria e a brincadeira também, nas práticas realizadas, as crianças aprendem e elas gostam de aprender. Na educação infantil e no ensino fundamental, o objetivo é atuar com liberdade para assegurar a apropriação e a construção do conhecimento por todos. Para a autora a inclusão de crianças de seis anos no ensino fundamental requer diálogo entre educação infantil e ensino fundamental, diálogo institucional e pedagógico, dentro da escola e entre as escolas, com alternativas curriculares claras.

Do outro lado do debate estão aqueles que, sem negar as dificuldades de iniciar o processo formal de alfabetização com crianças que não tiveram acesso à educação préescolar, alertam para o risco de transformar o $1^{\circ}$ ano do ensino fundamental em uma etapa da educação infantil, e, conseqüentemente, retardar o início do processo de aquisição de leitura e escrita justamente das crianças de nível socioeconômico mais baixo. Esta atitude traria como conseqüência o aumento do atraso escolar, já bastante significativo. As pesquisas conduzidas utilizando os dados do Censo Escolar e das PNADs (KLEIN, 2006), revelam que a taxa de conclusão do ensino fundamental na idade correta é de apenas $44 \%$, embora $1 / 4$ destes tenham uma repetência, e que a repetência na $1^{a}$ série seja de $30 \%$. A introdução dos ciclos de alfabetização de dois anos, em algumas unidades da Federação, apenas mascarou o problema, pois subiram as taxas de repetência no ano final do ciclo.

Embora, a rigor, todos concordem que um grande número escolas de ensino fundamental não estejam adequadamente preparadas para receber alunos dessa faixa etária, inclusive com mobiliário, equipamentos e materiais didáticos pertinentes, as crianças de seis anos chegaram às escolas para o início da escolaridade obrigatória, e essa é uma decisão política educacional irreversível. Compete agora a nós, educadores, decidir o que fazer com elas.

A presente pesquisa tem essa intenção: investigar como aprendem as crianças de seis anos oferecendo algumas evidências sobre os níveis de habilidades de leitura, escrita e de matemática alcançados por alunos matriculados no $1^{\circ}$ ano do ensino fundamental, nas redes municipais e estadual do Rio Grande do Sul.

\section{O projeto de alfabetização de crianças com seis anos: breve contextualização}

$\bigcirc$ projeto insere-se na meta mobilizadora de que nenhuma criança fique sem saber ler e escrever ao final do $2^{\circ}$ ano do ensino fundamental do governo do Rio Grande do Sul e, para atingi-la, o Plano de Governo propõe avaliar a alfabetização, nos dois primeiros anos do ensino fundamental.

Assim, em 2007, nos primeiros meses do ano letivo a Secretaria da Educação, em parceria com a União Nacional de Dirigentes Municipais de Educação - UNDIME/RS, implementaram o Projeto-Piloto para Alfabetização de Crianças com 6 Anos, diretamente articulado com as metas do Todos pela Educação e da Agenda 2020 e com as iniciativas do Ministério da Educação - MEC, no âmbito do Plano de Desenvolvimento da Educação - PDE. 
Este projeto teve o apoio do Escritório Antena da UNESCO no Rio Grande do Sul, Associação de Escolas Superiores de Formação de Profissionais do Ensino - AESUFOPE, e Federação das Associações de Círculos de Pais e Mestres do Rio Grande do Sul - ACPM/Federação.

Para sua realização a Secretaria da Educação buscou apoio na iniciativa privada e obteve recursos financeiros junto a empresas e entre elas a Aracruz, Copesul, Família Sirotsky, Gerdau, Marco Polo e a Refinaria Alberto Pasqualini - Refap.

O Projeto iniciado em 2007 tem continuidade nos anos de 2008 e 2009 com financiamento do MEC, no âmbito do convênio firmado pela Secretaria de Estado da Educação com o Ministério, relativo às ações previstas no Plano de Desenvolvimento da Educação - PDE.

Em 2008, o Projeto está em desenvolvimento nas turmas de $2^{\circ}$ ano do ensino fundamental de nove anos com crianças de sete anos de idade, que participaram do Projeto em 2007, e em novas turmas de $1^{\circ}$ ano com alunos de seis anos que, em 2009 , serão atendidas no $2^{\circ}$ ano.

\section{O Modelo da pesquisa}

Para a construção da matriz de habilidades e competências de leitura, escrita e matemática passíveis de serem alcançadas pelos alunos mediante diferentes propostas pedagógicas, foram convidadas três instituições com reconhecimento em âmbito nacional e comprovada competência na área da educação, especialmente da alfabetização e da avaliação escolar, para capacitar professores alfabetizadores ao longo do período de duração do Projeto e, ao final, estabelecerem um ponto comum de chegada, em termos de competências e habilidades cognitivas passíveis de serem desenvolvidas com crianças nesta faixa etária:

- Métodol adota para a alfabetização de crianças de seis e sete anos, um método fônico que estabelece relações explícitas entre os fonemas e grafemas, utilizando materiais estruturados e com forte controle morfossintático.

- Método 2 que promove ações para fortalecer a gestão do ensino e da aprendizagem, assegurando $95 \%$ de alfabetização no primeiro ano, mediante sistemática de acompanhamento e análise de resultados para a tomada de decisões.

- Método 3 que desenvolve programa de alfabetização com bases teóricas do pós-construtivismo (psicogênese da alfabetização - níveis pré-silábico, silábico e alfabético e interação social nas aprendizagens).

Para garantir a presença de professores e alunos de diferentes regiões do Estado no projeto, dividiu-se o Rio Grande do Sul em três grandes regiões - sul, nordeste e norte - seguindo modelo fornecido pela Secretaria de Estado do Planejamento e Gestão, com o objetivo de criar três pólos de turmas em cada uma das regiões, cada pólo responsável pela aplicação de um dos programas de intervenção pedagógica, de forma que os três programas se fizessem presentes nas três regiões. 
Abriu-se a inscrição para que Secretarias Municipais de Educação e, em um segundo momento, escolas públicas da rede estadual, através das Coordenadorias Regionais de Educação, aderissem a um dos programas nas três grandes regiões, num total de 200 turmas em cada região, com a condição de que, em um município, apenas um dos programas de intervenção pedagógica fosse desenvolvido.

\section{Grupos de Intervenção}

Deste processo, resultou ao final do projeto, a seguinte distribuição de escolas, turmas, professores e alunos entre as três instituições formadoras, nas três grandes regiões de abrangência do projeto:

Método 1.

\begin{tabular}{|l|c|c|c|c|}
\hline REGIÕES & No ESCOLAS & No TURMAS & No PROFESSORES & № ALUNOS \\
\hline REGIÃO NORDESTE & 44 & 58 & 55 & 1.594 \\
\hline REGIÃO NORTE & 33 & 37 & 37 & 819 \\
\hline REGIÃO SUL & 47 & 54 & 54 & 1.183 \\
\hline TOTAL & 124 & 149 & 146 & 3.596 \\
\hline
\end{tabular}

Fonte: RIO GRANDE DO SUL (2008).

Método 2.

\begin{tabular}{|l|c|c|c|c|}
\hline REGIÕES & No ESCOLAS & No TURMAS & No PROFESSORES & № ALUNOS \\
\hline REGIÃO NORDESTE & 70 & 70 & 68 & 1.601 \\
\hline REGIÃO NORTE & 48 & 50 & 46 & 1.093 \\
\hline REGIÃO SUL & 52 & 56 & 54 & 1.182 \\
\hline TOTAL & 170 & 176 & 168 & 3.876 \\
\hline
\end{tabular}

Fonte: RIO GRANDE DO SUL (2008).

Método 3.

\begin{tabular}{|l|c|c|c|c|}
\hline REGIÕES & No ESCOLAS & № TURMAS & No PROFESSORES & № ALUNOS \\
\hline REGIÃO NORDESTE & 43 & 63 & 51 & 1.464 \\
\hline REGIÃO NORTE & 40 & 45 & 43 & 999 \\
\hline REGIÃO SUL & 55 & 59 & 57 & 1.265 \\
\hline TOTAL & 138 & 167 & 151 & 3.728 \\
\hline
\end{tabular}

Fonte: RIO GRANDE DO SUL (2008).

As três instituições responsáveis pelos métodos capacitaram professores e gestores, disponibilizaram material didático adequado a cada programa, acompanharam o processo ensino-aprendizagem e aplicaram avaliações formativas aos alunos em diferentes momentos do ano letivo. 
A Secretaria de Estado da Educação manteve uma equipe composta por três assessoras técnico-pedagógicas para acompanhar as atividades do projeto, sendo cada uma responsável pela comunicação com um dos programas de intervenção pedagógica. Além disso, o projeto contou com pessoas responsáveis pelos programas nas Coordenadorias Regionais de Educação - CREs e Secretarias Municipais de Educação SMEs, incumbidas de acompanhar e assessorar o trabalho desenvolvido por meio de visitas às escolas e reuniões pedagógicas com as equipes diretivas e professores.

As Coordenadorias Regionais de Educação e os Municípios participantes do projeto foram os seguintes:

\begin{tabular}{|c|c|c|}
\hline CRE & Sede & Municípios no Projeto Piloto de Alfabetização \\
\hline $1^{a}$ & Porto Alegre & Porto Alegre \\
\hline $2^{a}$ & São Leopoldo & Igrejinha \\
\hline $4^{a}$ & Caxias do Sul & Caxias do Sul, Farroupilha, São Marcos \\
\hline $5^{a}$ & Pelotas & $\begin{array}{l}\text { Pelotas, Herval, Pedro Osório, Piratini, São Lourenço do } \\
\text { Sul, Arroio Grande, Jaguarão, Pinheiro Machado }\end{array}$ \\
\hline $6^{a}$ & Santa Cruz do Sul & $\begin{array}{l}\text { Santa Cruz do Sul, Rio Pardo, Mato Leitão, } \\
\text { Sobradinho, Venâncio Aires, Encruzilhada }\end{array}$ \\
\hline $7^{a}$ & Passo Fundo & $\begin{array}{l}\text { Passo Fundo, Lagoa Vermelha, Nonoai, } \\
\text { Marau, Caseiros, Ibirapuitã, Tapejara, Sertão }\end{array}$ \\
\hline $9^{a}$ & Cruz Alta & Ibirubá, Salto do Jacuí \\
\hline $12^{a}$ & Guaíba & $\begin{array}{l}\text { Guaíba, Arroio do Ratos, Barra do Ribeiro, Butiá, } \\
\text { Camaquã, Charqueadas, General Câmara, } \\
\text { São Jerônimo, Tapes, Sentinela do Sul, Chuvisca }\end{array}$ \\
\hline $13^{a}$ & Bagé & Bagé, Dom Pedrito, Caçapava do Sul, Candiota, Aceguá \\
\hline $14^{a}$ & Santo Ângelo & Santo Ângelo \\
\hline $15^{a}$ & Erechim & Erechim, Sananduva, Machadinho \\
\hline $16^{a}$ & Bento Gonçalves & Bento Gonçalves, Serafina Corrêa \\
\hline $18^{a}$ & Rio Grande & Rio Grande \\
\hline $19^{a}$ & Santana do Livramento & Santana do Livramento \\
\hline $20^{a}$ & Palmeiras das Missões & Frederico Westphalen \\
\hline $21^{a}$ & Três Passos & Santo Augusto, Três Passos, Crissiumal \\
\hline $24^{a}$ & Cachoeira do Sul & Cachoeira do Sul \\
\hline $25^{a}$ & Soledade & Soledade, Espumoso, Fontoura Xavier, Tapera, Arvorezinha \\
\hline $27^{a}$ & Canoas & Sapucaia do Sul, Nova Santa Rita, \\
\hline $28^{a}$ & Gravataí & Viamão \\
\hline $32^{a}$ & São Luiz Gonzaga & São Luiz Gonzaga, Porto Xavier \\
\hline $35^{a}$ & São Borja & Santiago \\
\hline $36^{a}$ & ljuí & ljuí, Jóia \\
\hline $39^{a}$ & Carazinho & Carazinho, Ronda Alta, Sarandi \\
\hline
\end{tabular}




\section{Grupo de controle}

Além das turmas - professores e alunos - que trabalharam com os três programas de intervenção pedagógica, participaram do projeto 169 turmas de controle. Os professores destas últimas não receberam formação continuada, porém os alunos realizaram o teste de prontidão e a avaliação final, de forma a possibilitar a comparação de seus resultados com os das turmas de intervenção

\section{A avaliação dos resultados}

A Fundação Cesgranrio foi a Instituição responsável por delinear o experimento, desenvolver os instrumentos de avaliação, corrigi-los, realizar as análises estatísticas para obter os resultados e elaborar as escalas de proficiências. Também foi sua atribuição desenvolver os boletins de resultados das turmas enviados a todas as escolas participantes do projeto.

\section{Instrumentos da Avaliação}

No mês de abril de 2007, os alunos foram submetidos a uma avaliação de prontidão mediante a aplicação de um teste realizado individualmente com cada aluno em uma entrevista conduzida por um professor aplicador treinado para essa atividade. Os resultados dessa testagem de prontidão deram origem a um boletim enviado para cada escola e turma.

Para avaliar os níveis de alfabetização em Leitura, Escrita e Matemática alcançados pelos alunos, foi desenvolvido um teste com questões originais composto por 10 questões de Leitura e Escrita, subdivididas em 31 itens e 19 de Matemática. Para a elaboração desse teste, os especialistas da Fundação Cesgranrio contaram com exemplos de questões enviadas pelos 3 métodos. Esse teste foi aplicado em dezembro de 2007 por professores treinados com um roteiro de aplicação e sessões de treinamento dos supervisores conduzidos pela Fundação Cesgranrio e equipe da Secretaria de Educação.

\section{Correção dos testes}

No mês de janeiro foram constituídas duas bancas de correção compostas por dez professores de Língua Portuguesa e oito de Matemática. Essas equipes participaram de um treinamento de correção e preenchimento das folhas óticas, com a duração de 8 horas. As primeiras 4 horas de correção posterior ao treinamento foram dedicadas à correção de uma amostra de 200 testes retirados de todos os municípios com a finalidade de testar e padronizar os critérios de correção. Os critérios de correção de Leitura e Escrita foram entregues à Secretaria de Educação e aos representantes dos 3 Métodos em uma reunião de apresentação de resultados realizada na sede da Secretaria de Educação no dia 26 de fevereiro de 2008.

\section{Resultados}

A correção dos testes atribuiu 1 ponto a cada item, assim o total de pontos em Leitura e Escrita é de 31 e em Matemática, 19. Posteriormente, as notas foram transformadas para a escala de 0 a 100. 
Os resultados serão apresentados através das medias obtidas pelos alunos dos quatro grupos e dos percentuais de alunos distribuídos nos diferentes níveis das escalas de 0 a 100.

Conforme dito anteriormente, não houve obediência a critérios amostrais probabilísticos para distribuir municípios e turmas pelos três métodos de intervenção. A escolha de cada qual foi livre pelos municípios e escolas envolvidas. Isto configura uma amostra intencional que não permite inferências a população de alunos das escolas públicas do Rio Grande do Sul. Os pesquisadores da Fundação Cesgranrio poderiam ter controlado algumas variáveis dos alunos, por exemplo, seu nível socioeconômico que possibilitaria obter relações entre este e o desempenho dos alunos, iá que o desempenho escolar costuma estar associado positivamente aos níveis socioeconômicos (KLEIN, 2006; SOARES, 2004). Entretanto, a comparação entre os métodos em termos da sua eficácia, não foi o objetivo da pesquisa. $\bigcirc$ que o projeto pretendeu oferecer, convidando diferentes abordagens, foi contemplar o pluralismo de experiências de Alfabetização.

É importante acrescentar também que, embora a discussão sobre métodos de alfabetização não seja consensual no Brasil, há bastante evidências científicas sobre o processo de aquisição de habilidades de leitura e escrita conforme mostrou o Relatório publicado pela Comissão de Educação e Cultura da Câmara dos Deputados (BRASIL, 2003).

Assim as tabelas apresentadas a seguir identificarão os métodos pelos números 1, 2 e 3 para evitar que interpretações equivocadas conduzam a conclusões de que um método obteve melhor resultado do que outro.

\begin{tabular}{|l|c|c|c|c|}
\hline Métodos & Presentes & Percentual & média & desvio padrão \\
\hline Geral & 11498 & 100.00 & 62.14 & 33.69 \\
\hline Método 1 & 2863 & 24.90 & 67.87 & 33.02 \\
\hline Método 2 & 3102 & 26.98 & 62.97 & 33.70 \\
\hline Método 3 & 2693 & 23.42 & 62.83 & 32.61 \\
\hline Controle & 2582 & 22.46 & 54.41 & 34.03 \\
\hline
\end{tabular}

Tabela 1 - Médias dos alunos em Leitura e Escrita por método.

Fonte: elaborada pelos Autores (2008).

Como se pode ver na tabela o desempenho dos alunos do grupo de controle é inferior ao dos alunos que participaram da intervenção pedagógica.

É necessário assinalar que em todos os 3 Métodos e no grupo de controle há turmas com alto e baixo desempenho. 


\begin{tabular}{|l|c|c|c|c|}
\hline Métodos & Presentes & Percentual & média & desvio padrão \\
\hline Geral & 11498 & 100.00 & 75.17 & 22.89 \\
\hline Método 1 & 2863 & 24.90 & 74.06 & 24.79 \\
\hline Método 2 & 3102 & 26.98 & 76.91 & 21.90 \\
\hline Método 3 & 2693 & 23.42 & 74.50 & 23.06 \\
\hline Controle & 2582 & 22.46 & 74.83 & 21.81 \\
\hline
\end{tabular}

Tabela 2 - Médias dos alunos em Matemática por método.

Fonte: elaborada pelos Autores (2008).

Na Matemática, o quadro é diferente, pois, praticamente, as médias são iguais, mesmo nas escolas de controle.

\section{A interpretação dos resultados}

Desde 1995 o Brasil vem descrevendo o desempenho dos alunos brasileiros em escalas de proficiências (KLEIN; FONTANIVE, 1995).

Nas escalas de proficiências, são escolhidos pontos para interpretar as habilidades que os alunos demonstram possuir quando seus desempenhos estão situados ao redor daquele ponto ou nível. Os pontos da escala do Sistema Nacional de Avaliação da Educação Básica - SAEB, foram arbitrados para conter o ponto 250 e a distância entre si de meio desvio padrão (25).

Os números das escalas do SAEB por si só não têm qualquer significado, da mesma maneira que a nota 7 ou o conceito $B$ só fazem sentido para o professor que elaborou questões, aplicou e corrigiu as provas (FONTANIVE; KLEIN, 2007). Entretanto, como o SAEB utiliza uma grande quantidade de itens para avaliar o desempenho dos alunos em uma área curricular ou disciplina - cerca de 130 a 169 - seria inadequado apresentá-los um a um para explicar os resultados obtidos. Então foi desenvolvida uma metodologia de interpretação dos níveis das escalas mediante a descrição dos conteúdos e habilidades que os alunos demonstraram possuir, quando acertam determinados itens aplicados.

Como se pode observar nas escalas apresentadas na página seguinte, os níveis indicam enunciados verbais que descrevem as habilidades que os alunos demonstram possuir quando seu desempenho se situa ao redor daquele nível na escala.

Para se chegar a essa descrição adota-se uma metodologia de interpretação de escalas apoiada em dois procedimentos.

\section{Identificação dos níveis Âncora da escala}

Para a interpretação das escalas obtidas são selecionados os itens que se posicionam em um determinado nível (ou ponto) da escala. A seleção desses itens para um nível da escala é feita a partir dos seguintes critérios:

- O número de alunos no nível que respondeu ao item é maior que 50. 
- $O$ percentual de acertos no item nos níveis anteriores é menor que 65\%.

- O percentual de acertos no item no nível considerado e nos níveis acima é maior que $65 \%$.

II. apresentação dos itens âncora a especialistas das áreas curriculares avaliadas, para que eles interpretem o que os alunos sabem, são capazes de fazer ou que habilidades demonstraram possuir para acertar aqueles itens.

Nos painéis, os especialistas contam com todos os itens utilizados na avaliação.

Eles dispõem também, para a discussão nos painéis, dos resultados estatísticos obtidos pelos itens. Eles podem, então, avaliar os índices de dificuldade de cada item, tipos de erros mais freqüentes cometidos pelos alunos, analisando a atração de uma alternativa errada, pelo percentual de alunos que a escolheram.

Com essas informações os especialistas chegam às descrições de cada um dos níveis das escalas.

A escala de 0 a 100 de Língua Portuguesa foi interpretada nos níveis 40, 60, 70, 80, 90 e 100. Após a obtenção dos itens âncora, esses níveis foram interpretados analisando-se as respostas dadas pelos alunos.aos itens.

A escala interpretada de Leitura e Escrita está apresentada a seguir:

\section{Escala de leitura e escrita}

\section{Nível 40}

Neste nível os alunos são capazes de relacionar palavras às figuras dadas.

Localizam em um conjunto de letras fornecidas as palavras que correspondem às figuras.

\begin{tabular}{|ccccc|}
\hline \multicolumn{5}{c|}{ \% Acima do Nível } \\
\hline Geral & Método 1 & Método 2 & Método 3 & Controle \\
67,8 & 74,5 & 68,7 & 68,2 & 58,7 \\
\hline
\end{tabular}

\section{Nível 60}

Neste nível os alunos demonstram a habilidade de localizar, em um texto de palavras simples do cotidiano, ditadas pelo professor.

Escrevem, com correspondência sonora alfabética e grafia correta ou, com desvios ortográficos do tipo troca do $\bigcirc$ pelo $U$ em posição átona final.

\begin{tabular}{|ccccc|}
\hline \multicolumn{5}{c|}{ \% Acima do Nível } \\
\hline Geral & Método 1 & Método 2 & Método 3 & Controle \\
56,6 & 65,2 & 57,4 & 56,4 & 46,2 \\
\hline
\end{tabular}




\section{Nível 70}

Neste nível os alunos demonstram a habilidade de escrever com correspondência sonora alfabética e grafia correta, incluindo a marca da nasalidade $\sim, \mathrm{m}$ ou $\mathrm{n}$.

Localizam em um texto do gênero fábula, palavras com certo grau de abstração, ditadas pelo professor.

\begin{tabular}{|ccccc|}
\hline \multicolumn{5}{c|}{ \% Acima do Nível } \\
\hline Geral & Método 1 & Método 2 & Método 3 & Controle \\
51,3 & 60,4 & 52,5 & 50,2 & 40,6 \\
\hline
\end{tabular}

\section{Nível 80}

Neste nível os alunos são capazes de localizar informações explicitas apresentadas em um texto do gênero fábula para redigir sua resposta.

Escrevem com correspondência sonora alfabética e com grafia correta incluindo dígrafos e encontros consonantais.

\begin{tabular}{|ccccc|}
\hline \multicolumn{5}{c|}{ \% Acima do Nível } \\
\hline Geral & Método 1 & Método 2 & Método 3 & Controle \\
44,4 & 53,4 & 45,5 & 43,2 & 34,2 \\
\hline
\end{tabular}

\section{Nível 90}

Os alunos demonstram a habilidade de localizar, em um texto do gênero fábula, uma informação sobre as preferências do personagem principal.

Produzem uma frase com algumas características de linguagem escrita, tais como omissão de palavras ou dificuldade em estabelecer a delimitação vocabular.

\begin{tabular}{|ccccc|}
\hline \multicolumn{5}{c|}{ \% Acima do Nível } \\
\hline Geral & Método 1 & Método 2 & Método 3 & Controle \\
34,4 & 42,8 & 35,9 & 31,8 & 26,1 \\
\hline
\end{tabular}

\section{Nível 100}

Os alunos neste nível identificam, no texto do gênero fábula e escrevem as características do personagem principal.

Produzem uma fase com características de linguagem escrita e do objetivo proposto, embora com desvios ortográficos compatíveis com a série/idade.

\begin{tabular}{|ccccc|}
\hline \multicolumn{5}{c|}{ \% Acima do Nível } \\
\hline Geral & Método 1 & Método 2 & Método 3 & Controle \\
8,7 & 11,6 & 9,9 & 7,0 & 5,6 \\
\hline
\end{tabular}




\section{Comentários}

Como se pode analisar, somente nos níveis mais altos da escala há domínio da habilidade de escrita. Este achado é compatível com os encontrados na avaliação dos alunos de São Paulo, por meio do Sistema de Avaliação de Rendimento Escolar do Estado de São Paulo - SARESP 2005 (SARESP, 2004).

A tabela 3 apresenta os percentuais acima dos níveis interpretados em Leitura e Escrita. Assim, acima do nível 80 estão, respectivamente, 44\% dos alunos participantes. No método 1, esse percentual é de 53\%, enquanto no Método 2 é $46 \%$, e no Método 3, é 43\%. No Controle, o percentual de alunos acima do nível 80 é de somente $34 \%$.

\begin{tabular}{|l|r|r|r|r|r|r|r|}
\hline & 0 & 40 & 60 & 70 & 80 & 90 & 100 \\
\hline Geral & 100.00 & 67.79 & 56.62 & 51.25 & 44.41 & 34.45 & 8.65 \\
\hline Método 1 & 100.00 & 74.51 & 65.23 & 60.40 & 53.44 & 42.82 & 11.58 \\
\hline Método 2 & 100.00 & 68.70 & 57.41 & 52.51 & 45.52 & 35.94 & 9.93 \\
\hline Método 3 & 100.00 & 68.15 & 56.37 & 50.22 & 43.25 & 31.85 & 7.05 \\
\hline Controle & 100.00 & 58.68 & 46.20 & 40.55 & 34.16 & 26.10 & 5.62 \\
\hline
\end{tabular}

Tabela 3 - Percentual dos alunos acima dos níveis da escala de 0 a 100 em Leitura e Escrita, por método.

Fonte: elaborada pelos Autores (2008).

A escala de 0 a 100 de Matemática foi interpretada nos níveis 21, 36, 47, 57, 63, $73,78,84,89$ e 94 . Após a obtenção dos itens âncora, os níveis foram interpretados analisando-se as habilidades solicitadas nas respostas dadas pelos alunos aos itens.

A escala interpretada de Matemática está apresentada a seguir. Na Matemática, os níveis correspondem ao número de acertos que vai de 0 a 19. Por exemplo, o nível 21 corresponde a aproximadamente 4 acertos na prova e o nível 36, a aproximadamente 7 acertos.

\section{Escala de matemática}

\section{Nível 21}

Os alunos são capazes de reconhecer a posição de objetos como "mais alto" e "dentro".

Identificar uma cédula de um valor dado e também relacionar produtos que são comprados com o litro.

\begin{tabular}{|ccccc|}
\hline \multicolumn{5}{c|}{ \% Acima do Nível } \\
\hline Geral & Método 1 & Método 2 & Método 3 & Controle \\
95,3 & 94,2 & 96,3 & 94,9 & 95,7 \\
\hline
\end{tabular}




\section{Nível 36}

Fazem contagem de elementos de uma coleção com menos de 10 elementos indicando o resultado por meio de escrita numérica.

\begin{tabular}{|ccccc|}
\hline \multicolumn{5}{|c|}{ \% Acima do Nível } \\
\hline Geral & Método 1 & Método 2 & Método 3 & Controle \\
93,5 & 91,8 & 94,6 & 93,4 & 94,2 \\
\hline
\end{tabular}

\section{Nível 47}

Os alunos nestes níveis completam uma seqüência numérica de números naturais até 10.

\begin{tabular}{|ccccc|}
\hline \multicolumn{5}{|c|}{ \% Acima do Nível } \\
\hline Geral & Método 1 & Método 2 & Método 3 & Controle \\
91,2 & 89,0 & 92,4 & 91,2 & 92,1 \\
\hline
\end{tabular}

\section{Nível 57}

Reconhecem um número menor que 10 em um calendário e resolvem situação problema envolvendo adição com número menor que 10.

\begin{tabular}{|ccccc|}
\hline \multicolumn{5}{|c|}{ \% Acima do Nível } \\
\hline Geral & Método 1 & Método 2 & Método 3 & Controle \\
85,8 & 83,4 & 87,1 & 85,8 & 87,0 \\
\hline
\end{tabular}

\section{Nível 63}

Completam uma seqüência formada por figuras geométricas.

\begin{tabular}{|ccccc|}
\hline \multicolumn{5}{c|}{ \% Acima do Nível } \\
\hline Geral & Método 1 & Método 2 & Método 3 & Controle \\
81,9 & 79,7 & 83,4 & 81,9 & 82,6 \\
\hline
\end{tabular}

\section{Nível 73}

Os alunos nestes níveis sabem transformar um número de dois dígitos da forma verbal para a escrita numérica.

\begin{tabular}{|ccccc|}
\hline \multicolumn{5}{|c|}{ \% Acima do Nível } \\
\hline Geral & Método 1 & Método 2 & Método 3 & Controle \\
69,5 & 68,7 & 71,1 & 68,9 & 69,2 \\
\hline
\end{tabular}

\section{Nível 78}

Resolvem uma situação problema que envolve a adição com números na ordem de dezenas, e relacionam o menor número em um conjunto de números de 11 a 19 .

\begin{tabular}{|ccccc|}
\hline \multicolumn{5}{|c|}{ \% Acima do Nível } \\
\hline Geral & Método 1 & Método 2 & Método 3 & Controle \\
60,0 & 60,5 & 62,2 & 57,8 & 59,4 \\
\hline
\end{tabular}




\section{Nível 84}

Os alunos possuem a habilidade de resolver uma situação problema que envolve o conceito de subtração com números até 10 .

\begin{tabular}{|ccccc|}
\hline \multicolumn{5}{c|}{ \% Acima do Nível } \\
\hline Geral & Método 1 & Método 2 & Método 3 & Controle \\
48,9 & 49,9 & 51,2 & 46,6 & 47,8 \\
\hline
\end{tabular}

\section{Nível 89}

Ordenam números até 10 , do menor para o maior.

\begin{tabular}{|ccccc|}
\hline \multicolumn{5}{c|}{ \% Acima do Nível } \\
\hline Geral & Método 1 & Método 2 & Método 3 & Controle \\
35,3 & 36,8 & 39,6 & 33,1 & 30,9 \\
\hline
\end{tabular}

\section{Nível 94}

Neste nível os alunos armam e efetuam soma e subtração de números naturais com dois algarismos, sem recurso/reserva.

\begin{tabular}{|ccccc|}
\hline \multicolumn{5}{c|}{ \% Acima do Nível } \\
\hline Geral & Método 1 & Método 2 & Método 3 & Controle \\
20,6 & 22,4 & 25,3 & 17,9 & 15,8 \\
\hline
\end{tabular}

A tabela 4 apresenta os percentuais acima dos níveis interpretados em Matemática. Assim, acima do nível 73 estão, respectivamente, 69\% dos alunos participantes.

\begin{tabular}{|l|r|r|r|r|r|r|r|r|r|r|r|}
\hline & 0 & 21 & 36 & 47 & 57 & 63 & 73 & 78 & 84 & 89 & 94 \\
\hline Geral & 100.00 & 95.28 & 93.48 & 91.19 & 85.79 & 81.90 & 69.48 & 60.05 & 48.95 & 35.31 & 20.59 \\
\hline Método 1 & 100.00 & 94.24 & 91.78 & 89.00 & 83.35 & 79.72 & 68.69 & 60.53 & 49.91 & 36.83 & 22.44 \\
\hline Método 2 & 100.00 & 96.29 & 94.55 & 92.42 & 87.07 & 83.37 & 71.05 & 62.22 & 51.19 & 39.59 & 25.31 \\
\hline Método 3 & 100.00 & 94.89 & 93.44 & 91.23 & 85.80 & 81.93 & 68.88 & 57.79 & 46.56 & 33.09 & 17.93 \\
\hline Controle & 100.00 & 95.66 & 94.15 & 92.14 & 86.99 & 82.57 & 69.17 & 59.41 & 47.83 & 30.95 & 15.80 \\
\hline
\end{tabular}

Tabela 4 - Percentual dos alunos acima dos níveis da escala de 0 a 100 em Matemática, por método.

Fonte: elaborada pelos Autores (2008).

\section{Controle socioeconômico dos alunos}

Os resultados das pesquisas educacionais vêm mostrando uma associação positiva entre o desempenho dos alunos medidos por testes de escolaridade e o nível socioeconômico e cultural das famílias dos alunos. As pesquisas voltadas para avaliar o efeito da escola na aprendizagem procuram controlar os resultados por variáveis socioeconômicas de modo a minimizar esse efeito. 
Em geral, esses dados são obtidos mediante a aplicação de questionários abordando os aspectos socioeconômicos ou os dados são obtidos por entrevistas diretas com os pais. No presente projeto, esses dados não foram pesquisados nem junto aos alunos nem aos pais. Entretanto para garantir que o efeito observado na aprendizagem dos alunos de leitura e escrita, nos grupos de intervenção e de controle, não se deveu a diferenças marcantes de níveis socioeconômicos entre os grupos. Buscou-se então uma proxy para o nível socioeconômico dos alunos mediante o uso do índice do Critério Brasil (CRITÉRIO..., 2003) obtido pelos questionários aplicados na Prova Brasil, no ano de 2007, aos alunos da $4^{a}$ série $/ 5^{\circ}$ ano do EF. A Prova Brasil é uma avaliação aplicada pelo INEP/MEC de forma censitária nas escolas públicas com pelo menos 20 alunos na $4^{a}$ e $8^{a}$ séries $\left(5^{\circ}\right.$ e $9^{\circ}$ ano) do EF.

Com os dados disponibilizados pelo INEP, as escolas participantes do Projeto intervenção e controle - foram identificadas e o índice médio do nível socioeconômico de seus alunos medido pelo Critério Brasil foi calculado para cada uma delas. Esse índice médio está sendo usado com a hipótese de que em uma mesma escola, não haja grandes variações do nível socioeconômico entre alunos de $1^{\circ}$ ao $5^{\circ}$ ano/ $4^{a}$ série. A tabela 5 mostra o número de escolas sem informação de NSE.

\begin{tabular}{|c|c|c|c|}
\hline CONTROLE & MÉTODO.1 & MÉTODO.2 & MÉTODO.3 \\
\hline 1 & 9 & 12 & 7 \\
\hline
\end{tabular}

Tabela 5 - Número de escolas sem informação de NSE.

Fonte: elaborada pelos Autores (2008).

A tabela 6 exibe os resumos das distribuições das médias de NSE dos alunos de cada escola por grupo de intervenção e controle, e a figura abaixo exibe o boxploł dessas distribuições. Como se pode ver não há indicação de diferenças entre as distribuições, embora o grupo de controle tenha uma distribuição de NSE ligeiramente mais deslocada para os níveis mais altos. Este fato nos dá mais confiança na asserção de que os resultados dos grupos de intervenção no processo de alfabetização em Leitura e Escrita com qualquer um dos métodos foram melhores que os do grupo de controle.

\begin{tabular}{|l|r|r|r|r|}
\hline & CONTROLE & MÉTODO.1 & MÉTODO.2 & MÉTODO.3 \\
\hline Mínimo & 12.14 & 12.32 & 12.17 & 11.66 \\
$1^{\circ}$ quartil & 15.62 & 14.80 & 15.32 & 14.26 \\
Mediana & 16.95 & 16.11 & 16.23 & 15.71 \\
Média & 16.83 & 16.02 & 16.31 & 15.62 \\
$3^{\circ}$ quartil & 17.90 & 17.24 & 17.14 & 16.87 \\
Máximo & 20.45 & 21.50 & 20.67 & 19.71 \\
\hline
\end{tabular}

Tabela 6 - Resumo das distribuições das médias de NSE das escolas por grupo de intervenção e controle.

Fonte: elaborada pelos Autores (2008). 


\section{Boxplot das médias de NSE das escolas por grupo}

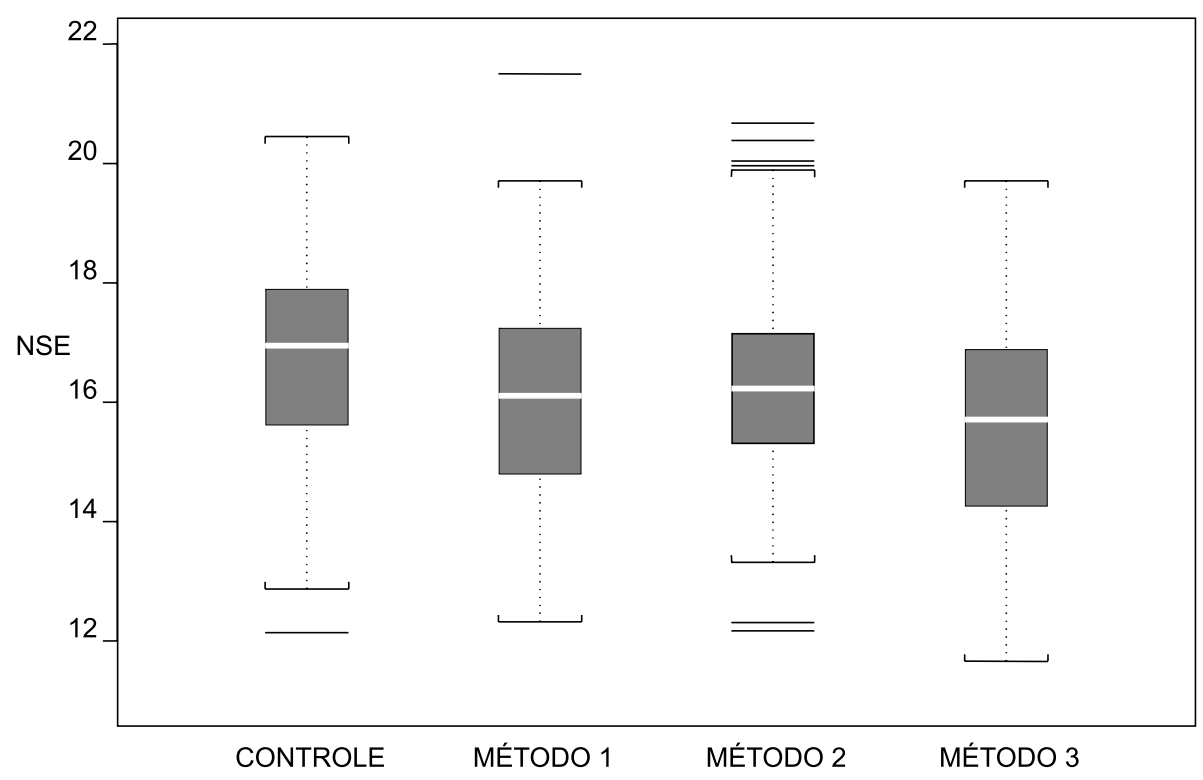

\section{Referências}

BRASIL. Congresso. Câmara dos Deputados. Comissão de Educação e Cultura. Grupo de Trabalho Alfabetização Infantil: os novos caminhos. In: SEMINÁRIO O PODER LEGISLATIVO E A ALFABETIZAÇÃO INFANTIL: novos caminhos, 2003, Brasília. Relatório final... Brasília, DF, 2003.

CRITÉRIO de Classificação Econômica Brasil. São Paulo: ABEP, 2003. Disponível em: <http://www.abep.org/codigosguias/ABEP_CCEB.pdf>. Acesso em: 11 nov. 2008.

FONTANIVE, N. S.; ELLIOT, L. G.; KLEIN, R. Os desafios da apresentação dos resultados da avaliação de sistemas escolares a diferentes públicos. Revista Electrónica Iberoamericana sobre Calidad, Eficacia y Cambio en Educación, Madrid, v. 5, n. 2e, p. 262-273, 2007. Disponível em: <http://redalyc.vaemex.mx/ redalyc/pdf/551/55150219.pdf>. Acesso em: 11 nov. 2008.

KLEIN, R. Como está a educação no Brasil? $\bigcirc$ que fazer? Ensaio: avaliação e políticas públicas em educação, Rio de Janeiro, v. 14, n. 51, p. 139-172, abr./jun. 2006.

KLEIN, R.; FONTANIVE, N. Avaliação em larga escala. Em Aberto, Brasília, DF, v. 15, n. 66, p. 29-34, 1995. 
KRAMER, $\mathrm{S}$. As crianças de 0 a 6 anos nas políticas educacionais no Brasil: educação infantil e/é fundamental. Educação e Sociedade, Campinas, SP, v. 27, n. 96 , out. 2006.

RIO GRANDE DO SUL. Secretaria da Educação. Projeto Piloto para Alfabetização de Crianças com Seis Anos. Porto Alegre, 2008. Disponível em: < http:// www.educacao.rs.gov.br/pse/html/proi_piloto.jsp? ACAO=acaol $>$. Acesso em: 10 ago. 2008.

SANTOS, L. C. P.; VIEIRA, L. M. F. Agora seu filho entra mais cedo na escola: a criança de seis anos no Ensino Fundamental de nove anos em Minas Gerais. Educação e Sociedade, Campinas, SP, v. 27, n. 96, out. 2006.

SÃO PAULO (Estado). SARESP 2005. São Paulo, 2004. Disponível em: <http:// saresp.fde.sp.gov.br/2005/subpages/conheca.htm>. Acesso em: 28 nov. 2008.

SOARES, J. F. Qualidade e eqüidade na educação básica brasileira: a evidência do SAEB-2001. Archivos Analíticos de Políticas Educativas, [Rio de Janeiro], v. 12, n. 38, p. 1-24, 2004.

Recebido em: 23/10/2008

Aceito para publicação em: 28/11/2008 